\title{
CellSave Blood Collection Tube
}

National Cancer Institute

\section{Source}

National Cancer Institute. CellSave Blood Collection Tube. NCI Thesaurus. Code C162038.

A proprietary blood collection tube designed for venous blood collection, containing EDT A anticoagulant and a cell preservative. The EDTA absorbs calcium ions, which prevents the blood from clotting. The preservative preserves the morphology and cell surface antigen expression of the epithelial cells and leukocytes. This blood collection tube has been used for the preservation of circulating tumor cells and lymphocyte subsets. 